\title{
COMPARAÇÃO DE TRÊS MÉTODOS PARA A MEDIÇÃO DA VAZÃO E VELOCIDADE APLICADOS EM DOIS CURSOS D'ÁGUA DA BACIA DO RIBEIRÃO MARINGÁ
}

Cássia Maria Bonifácio ${ }^{1}$

Rosane Freire $^{2}$

RESUMO: O objetivo deste trabalho foi comparar os resultados de medição de vazão hídrica obtidos pelos métodos do flutuador, molinete hidrométrico e do método acústico por meio de medições em dois corpos d'água: córrego Romeira e ribeirão Maringá, localizados no município de Maringá - PR. Estes cursos d'água possuem fluxos e leitos distintos, contudo apresentam as mesmas características geológica e climática. Os resultados mostraram diferenças significativas no valor das vazões. O método acústico foi o mais indicado para a realização das medições, já o molinete mostrou ser uma alternativa viável, e o método do flutuador apresentou o maior erro relativo, sendo passível de utilização para fins didáticos e somente se não houver alternativa para a medição.

Palavras-chave: Flutuador. Molinete Hidrométrico. Método Acústico.

\section{INTRODUÇÃO}

\footnotetext{
${ }^{1}$ Geógrafa, Mestre em Geografia, Pesquisadora Bolsista CNPQ/FINEP. Universidade Estadual de Maringá. Email: kaoruyuri@hotmail.com

${ }^{2}$ Engenharia Ambiental, Mestre e Doutora em Engenharia Química. Universidade Estadual de Maringá. Email: rofreire@gmail.com
} 
O conhecimento dos parâmetros ou das variáveis hidrológicas é de grande relevância para o planejamento e gestão dos recursos hídricos, promovendo sugestões para medidas mitigadoras, no caso de ocorrência de impactos ao meio ambiente e à quantidade e qualidade de água, para as diferentes formas de uso. Desse modo, os dados de vazão são importantes para estimar, por exemplo, o volume de água para o abastecimento humano, além da possível previsão e prevenção de inundações e enchentes, ou do volume mínimo de água sem prejuízo ecológico.

A vazão é definida pelo volume de água que passa por uma área na unidade de tempo, sendo o valor expresso em metros cúbicos por segundo $\left(\mathrm{m}^{3} / \mathrm{s}\right)$. A quantidade de água que atinge os cursos d'água depende das características físicas da bacia hidrográfica em estudo: área, forma, sistema de drenagem, relevo, além da precipitação total e seu regime de perdas por evaporação, transpiração e infiltração (TUCCl, 1997).

A vazão dos cursos d'água pode ser influenciada pelo clima, aumentando durante os períodos de precipitação e diminuindo nos períodos de estiagem. Sua medição é importante, pois influencia a qualidade da água, além dos organismos que nela vivem. Seu estudo também se faz necessário para o planejamento urbano, uma vez que corrobora para a previsão e precaução de enchentes.

Contudo, existem muitas técnicas e equipamentos para a realização das medidas de vazão, entre eles estão o flutuador, o molinete e o método acústico. Alguns são indicados para trabalhos em cursos d'água de pequeno e médio porte, e outros para médio e grande porte. A escolha entre as formas de medição de vazão está muitas vezes ligada à disponibilidade dos equipamentos (custos) e ao tempo de coleta de dados que estes necessitam.

A medição por meio do flutuador é recomendada para trabalhos que não exigem tanta precisão, em cursos d'água pequenos, pois nesta técnica muitas variáveis podem influenciar nos resultados, como: tipo do leito (barrento ou pedregoso), forma do canal (é necessário escolher um trecho longo e retilíneo), vento (pode aumentar a velocidade do flutuador), quantidade de medições (reflete diretamente na qualidade estatística dos dados). No método, deve-se realizar a separação do curso d'água em seções, medir a 
profundidade, além da necessidade de duas pessoas (uma na seção à montante e outra na porção à jusante) para acompanhar a medição do tempo (PALHARES et al., 2007) .

Já o molinete é um equipamento tradicional nas medições de vazão. Agindo por meio da rotação da hélice em relação ao fluxo d'água, pode ser utilizado para cursos d'água de pequeno, médio e grande porte. As medições podem ser realizadas manualmente no local ou, em determinadas situações, com o auxílio de um barco. Nesse método, é necessário calcular a seção transversal do corpo hídrico no local. A obtenção de melhores resultados também é influenciada pela quantidade de medições. Dependendo das dimensões do rio, no caso de grande porte, são necessárias no mínimo 20 medições individuais ao longo da seção, além da utilização do barco em cursos d'água largos e profundos. Sendo assim, as medições podem levar muitas horas (RICARDO et al., 2008).

O equipamento de medição que utiliza o método acústico para quantificação da vazão é mais moderno em relação ao molinete. É utilizado para cursos d'água de médio e grande porte. Segundo Simpson (2001), este equipamento permite a realização de medições em condições ambientais adversas (cheias, refluxos, seções geometricamente inadequadas para a medição com flutuadores e molinetes), pois essas condições são medidas e consideradas no cálculo final da vazão. A seção transversal é calculada automaticamente pelo aparelho. Além disso, as medições são significativamente mais rápidas, durando minutos ao invés de horas (MORLOCK, 1996). Contudo, este equipamento é menos acessível em relação aos outros pelo seu custo financeiro (RICARDO et al., 2008).

Para verificar as vantagens e desvantagens de cada método em termos de dados obtidos, foram realizadas medidas de vazão com os três métodos: flutuador, molinete e o método acústico, em dois cursos d'água do município de Maringá-PR: córrego Romeira e ribeirão Maringá. Esses corpos hídricos diferem quanto à quantidade de fluxo d'água e tipo de leito, contudo possuem as mesmas características geológicas e climáticas.

Neste trabalho procurou-se verificar qual a metodologia mais indicada para cada curso d'água (levando em consideração o custo, tempo e eficiência) e comparar estatisticamente os resultados e variações que estas metodologias podem apresentar 
para bacias hidrográficas que apresentam características semelhantes. Sendo assim, este estudo se torna importante para nortear trabalhos futuros relacionados à temática.

\section{METODOLOGIA}

As medições de velocidade e vazão foram realizadas em um trecho do córrego Romeira e um trecho do ribeirão Maringá, localizados na área rural do município de Maringá - PR, no período da manhã do dia 19/04/2011. Esses dois trechos foram escolhidos tendo em vista a facilidade de acesso, a linearidade do trecho, a homogeneidade da seção transversal, ausência de obstáculos, tais como galhadas, e profundidade acessível para a tomada de dados, como precavido por ALMEIDA JÚNIOR (2010).

Para a estimativa da velocidade e vazão foram utilizados três métodos: método do flutuador; o micromolinete hidrométrico; e, o método acústico utilizando o instrumento Flowtracker da Sontek ${ }^{\circledR}$.

Como os três métodos utilizam a relação velocidade e área para a determinação da vazão foi necessário estabelecer uma seção transversal de referência. Inicialmente foi obtida a largura da seção do rio, com auxílio de uma trena. Em seguida, essa seção foi dividida em uma série de verticais igualmente separadas, onde foram medidas suas respectivas profundidades.

O cálculo da área da seção transversal é dado pela soma das áreas de influência formadas em cada vertical, como apresentado na Equação 1. A área de influência para cada vertical foi dada pelo produto entre distância média entre cada vertical e a profundidade. Nas margens considerou-se a área como sendo a aproximação da área de um triângulo.

$$
A_{T}=\sum_{i=1}^{n} A i
$$

Em que:

$A_{T}=$ Área da seção transversal $\left(\mathrm{m}^{2}\right)$;

$n=$ número de verticais; 
$A_{i}=$ Área transversal na seção i $\left(\mathrm{m}^{2}\right)$.

No método do flutuador foi necessário formar duas seções, com espaçamento de 6,0 metros entre elas. A área da seção transversal foi definida pela média da seção molhada a montante e a jusante. Na Figura 1 é possível observar como foram definidas as seções transversais nos cursos d'água em estudo.

A)

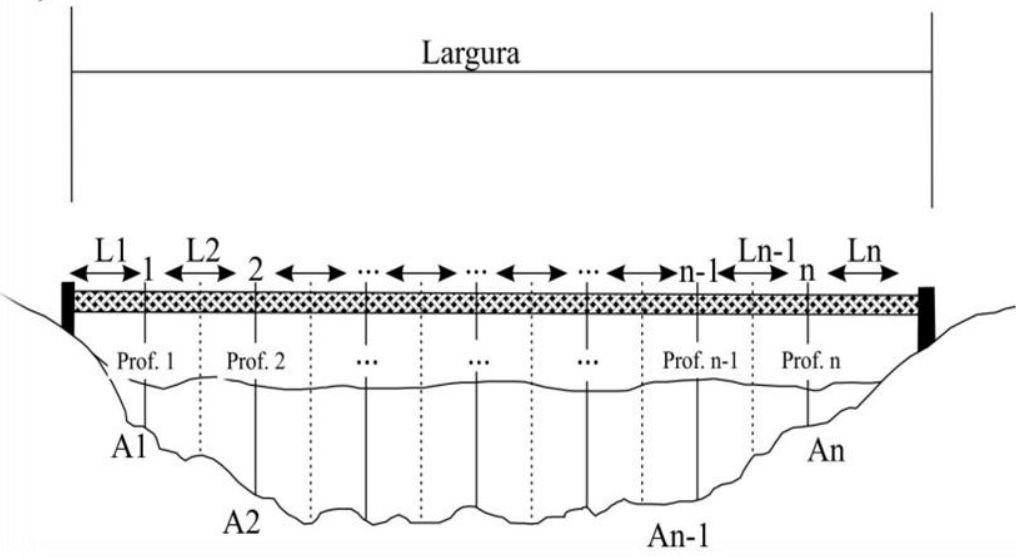

B)

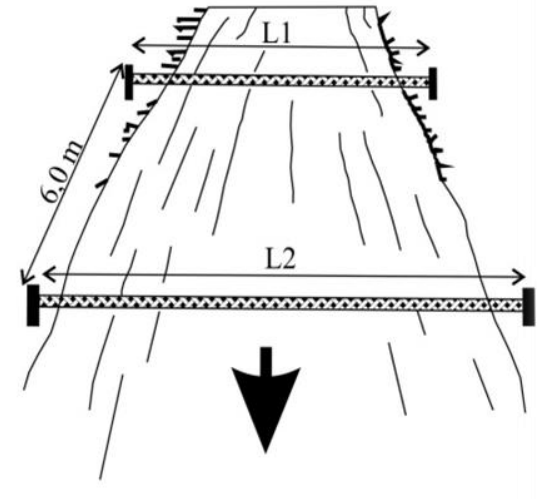

Figura 1 - Definição das seções transversais: A) Método do molinete e método acústico. B) Método do flutuador (Adaptado de EPA, 1997 e Santos et al. 2001).

A velocidade com o uso do método do flutuador foram obtidas seguindo as orientações de Palhares et al. (2007), empregando como objeto flutuante uma bolinha de isopor e determinando o tempo gasto para que a mesma percorra a distância entre seção a montante e a jusante $(6,0 \mathrm{~m})$. Uma série de vinte repetições foi estabelecida e os valores máximos e mínimos encontrados foram excluídos para a estimativa da velocidade média.

A vazão total pelo método do flutuador é dada pelo do produto da velocidade média corrigida pela área de seção transversal média. Ainda, como proposto pela Environmental Protection Agency - EPA (1997) foi estabelecido um coeficiente de correção para vazão na ordem de 0,80 para o córrego Romeira, visto que este apresenta fundo arenoso, e um coeficiente de correção de 0,90 para o ribeirão Maringá, 
considerando que este apresentou fundo pedregoso no local de medição. O uso do coeficiente de correção se faz necessário devido ao fato de a água se deslocar mais rapidamente na superfície do que na porção do fundo do rio (PALHARES et al., 2007).

Com o molinete, a velocidade foi estimada marcando o número de giros dados pela hélice do molinete no intervalo de 60 segundos e, posteriormente, transpondo esse valor para a equação de conversão fornecida pelo fabricante do equipamento. Em cada vertical foram realizadas duas repetições. A vazão total é dada pelo somatório dos produtos da velocidade para cada vertical pela área de influência de cada vertical, como apresentado na Equação 2.

$$
Q_{\text {Total }}=\sum_{i=1}^{n} v_{i} A_{i}
$$

Equação 2

Em que:

$Q_{\text {Total }}=\operatorname{vazão}$ total $\left(\mathrm{m}^{3} / \mathrm{s}\right)$;

$n=$ número de verticais;

$v_{i}=$ velocidade média na seção i $(\mathrm{m} / \mathrm{s})$;

$A_{i}=$ área transversal da seção i $\left(\mathrm{m}^{2}\right)$.

No caso do método acústico, o princípio envolvido na mensuração da velocidade é o efeito doppler que diz: "se uma fonte de som está se movendo com relação ao receptor, a frequência do som no receptor é diferente da frequência de transmissão" (FERNANDES, 2009). A coleta de dados pelo equipamento foi instantânea, contudo houve a necessidade de inserir previamente as características de profundidade e de largura da vertical. O modo de coleta de dados foi a seção média e, como esse equipamento possui o tratamento estatístico automático, ou seja, foi previamente definido um desvio padrão máximo na média dos dados coletados de 0,01 . As repetições foram realizadas apenas quando o equipamento solicitou uma nova tomada de dados.

Utilizando o molinete e o método acústico, em cada vertical a velocidade foi tomada a 0,6 da profundidade total, seguindo as recomendações de Santos et al. (2001). 


\section{RESULTADOS}

A caracterização morfológica do canal bem como os resultados médios obtidos na estimativa da velocidade $(\mathrm{m} / \mathrm{s})$, vazão $\left(\mathrm{m}^{3} / \mathrm{s}\right)$ e seus respectivos desvios-padrão, com os três métodos de mensuração para o trecho do córrego Romeira e o trecho do ribeirão Maringá, são apresentados na Tabela 1.

Em uma primeira análise dos resultados, observou-se que os dois trechos estudados possuem profundidades bem próximas, mas apresentam largura de leito bem distintas, proporcionando características hidráulicas diferentes.

Tabela 1 - Caracterização morfológica do canal, velocidade $(\mathrm{m} / \mathrm{s})$ e vazão $\left(\mathrm{m}^{3} / \mathrm{s}\right)$ para o trecho do córrego Romeira e o trecho do ribeirão Maringá.

\begin{tabular}{lc|lc}
\hline \multicolumn{3}{c}{ Córrego Romeira } & \multicolumn{2}{c}{ Ribeirão Maringá } \\
\hline \multicolumn{3}{c}{ Características Morfológicas } \\
\hline Largura $(\mathrm{m})$ & 1,60 & Largura $(\mathrm{m})$ & 4,5 \\
Prof. Média $(\mathrm{m})$ & 0,34 & Prof. Média $(\mathrm{m})$ & 0,32 \\
$\mathrm{~A}\left(\mathrm{~m}^{2}\right)$ & 0,55 & A $\left(\mathrm{m}^{2}\right)$ & 1,62 \\
Fundo arenoso & & Fundo pedregoso \\
\hline \multicolumn{4}{c}{ Velocidade Média (m/ s) } \\
\hline Método & $0,287 \pm 0,01$ & Método \\
acústico & acústico & $0,218 \pm 0,01$ \\
Molinete & $0,349 \pm 0,03$ & Molinete & $0,211 \pm 0,02$ \\
Flutuador & $0,422 \pm 0,08$ & Flutuador & $0,322 \pm 0,04$ \\
\hline \multicolumn{4}{c}{ Vazão Média (m $\left.{ }^{3} / \mathbf{s}\right)$} \\
\hline Método & $0,157 \pm 0,01$ & Método \\
acústico & acústico & $0,353 \pm 0,01$ \\
Molinete & $0,193 \pm 0,04$ & Molinete & $0,333 \pm 0,04$ \\
Flutuador & $0,209 \pm 0,04$ & Flutuador & $0,418 \pm 0,05$ \\
\hline
\end{tabular}


.O trecho do córrego Romeira é mais estreito o que confere maior velocidade as suas águas, embora apresente vazão mais baixa em virtude da menor área de seção transversal. No ribeirão Maringá, entretanto, apesar do maior comprimento de leito e, consequentemente, maior área de escoamento e descarga líquida, suas águas são mais tranquilas. Tais resultados concordam com aqueles obtidos nos estudos de Schneider (2009) nos cursos d'água da bacia do ribeirão Maringá.

Em termos de comparação entre os métodos de medição de velocidade e vazão em cursos d'água, observou-se que em nenhum momento houve proximidade dos resultados médios obtidos com os equipamentos utilizados, apesar dos desvios-padrão para cada método utilizado serem baixos. Esta constatação também foi observada em outros estudos comparativos utilizando métodos semelhantes, tais como Almeida Júnior et al. (2010), Ricardo et al. (2008), Melchior (2006), entre outros.

Em termos de erros relativos na mensuração da vazão e, considerando o método acústico como parâmetro de comparação, devido à precisão na forma de aquisição e tratamento de dados, no trecho do córrego Romeira os erros foram da ordem de $23 \% \mathrm{com}$ o uso de molinete e de $31 \%$ com o emprego do método do flutuador. De modo análogo, no trecho do ribeirão Maringá esses erros foram de 6\% e 18\%, respectivamente.

\section{CONSIDERAÇÕES FINAIS}

Tomando como base a elevada precisão do equipamento para medição de vazão pelo método acústico, os resultados obtidos mostraram uma grande variação entre os métodos do molinete hidrométrico e do flutuador. Isto indica que a aquisição de dados pelos referidos métodos supracitados não representou fielmente a realidade dos cursos d'água em estudo. Neste aspecto, cabe observar que diante de uma situação de escolha de métodos de medição, devem-se procurar equipamentos que possuam tecnologias de precisão e controle de dados. Em relação aos erros, o molinete mostrou ser uma alternativa viável. O método do flutuador apresentou o maior erro relativo para a estimativa da vazão nos dois cursos d'água. Assim, esse método não deve ser utilizado 
ou empregado ao menos se, e somente se, não houver alternativa viável para a mensuração.

\section{REFERÊNCIAS}

ALMEIDA JÚNIOR, A. J. C. D., HERNANDEZ, F. B. T., FRANCO, R. A. M., ZOCOLER, J. L. Medição de Velocidade e Vazão em Cursos D'Água: Molinete Hidrométrico versus Método do Flutuador. In: CONGRESSO NACIONAL DE IRRIGAÇÃO E DRENAGEM. Anais..., ABID, Uberaba, 2010.

EPA. ENVIRONMENTAL PROTECTION AGENCY. Stream Flow. In: Office Of Water: Monitoring Water Quality. Volunteer stream monitoring: a methods manual. Washignton: EPA, 1997. Cap 5, p. 134-138.

FERNANDES, J. C. Acústica e ruídos. Apostila. Depto de Engenharia Mecânica. Faculdade de Engenharia UNESP - Campus Bauru, 2009.

FREIRE, R. Monitoramento da qualidade da água da bacia hidrográfica do ribeirão Maringá. 2010. 199p. Dissertação (Mestrado em Engenharia Química) Departamento de Engenharia Química. Universidade Estadual de Maringá, Maringá.

FRAGOSO JR, C. R., SOUZA, C. F., GIACOMONI, M. H. Vazão ecológica constante vs. Vazão ecológica variável. In: VII Simpósio de Recursos Hídricos do Nordeste. Anais..., VII SRHN, 2004.

MELCHIOR, C. Comparativo de Resultados de Medição de Vazão pelos Métodos: Convencional e Acústico. 2006. 72p. Trabalho Final de Graduação (Graduação em Engenharia Civil). União Dinâmica de Faculdades Cataratas, Foz do Iguaçu.

MORLOCK, S. E. Evaluation of acoustic Doppler current profiler measurements of river discharge. In: USGS, Washington. 1996.

PALHARES, J. C. P., RAMOS, C., KLEIN, J. B., LIMA, J. M. M., MULLER, S., CESTONARO, T. Medição da Vazão em Rios pelo Método do Flutuador. EMBRAPA, Comunicado Técnico 455, Concordia - SC, 2007. ISSN 0100-8862.

RICARDO, M., VIANA, A. N. C., SILVA, L. F., BERNARDES, M. E. C. Análise e Aplicação de Perfiladores Acústicos Doppler para Medição de Vazão de Pequenas Centrais Hidrelétricas. In: VI SIMPÓSIO BRASILEIRO SOBRE PEQUENAS E MÉDIAS CENTRAIS HIDRELÉTRICAS. Anais... Comitê Brasileiro de Barragens, Belo Horizonte, 2008. 
SANTOS, I., FILL, H. D., SUGAI, M. R. B., BUBA, H., KISHI, R. T., MARONE, E., LAUTERT, L. F. C. Hidrometria Aplicada. Curitiba: LACTEC - Instituto de Tecnologia para o Desenvolvimento. 2001, 372 p. 